\title{
Japanese Young Women Did not Discriminate between Robots and Humans as Listeners for Their Self-Disclosure -Pilot Study-
}

\author{
Takahisa Uchida ${ }^{1,2, *}$, Hideyuki Takahashi ${ }^{1}$, Midori Ban ${ }^{1}$, Jiro Shimaya ${ }^{1}$, Takashi Minato ${ }^{2}$, \\ Kohei Ogawa ${ }^{1}$, Yuichiro Yoshikawa ${ }^{1}$ and Hiroshi Ishiguro ${ }^{1,2}$ \\ 1 Graduate School of Engineering Science, Osaka University, Osaka 560-853, Japan; \\ takahashi@irl.sys.es.osaka-u.ac.jp (H.T.); ban@irl.sys.es.osaka-u.ac.jp (M.B.); \\ shimaya.jiro@irl.sys.es.osaka-u.ac.jp (J.S.); ogawa@irl.sys.es.osaka-u.ac.jp (K.O.); \\ yoshikawa@irl.sys.es.osaka-u.ac.jp (Y.Y.); ishiguro@irl.sys.es.osaka-u.ac.jp (H.I.) \\ 2 Advanced Telecommunications Research Institute International (ATR), Kyoto 619-0288, Japan; minato@atr.jp \\ * Correspondence: uchida.takahisa@irl.sys.es.osaka-u.ac.jp; Tel.: 81+6-6850-6360
}

Received: 15 May 2020; Accepted: 24 June 2020 ; Published: 30 June 2020

\begin{abstract}
Disclosing personal matters to other individuals often contributes to the maintenance of our mental health and social bonding. However, in face-to-face situations, it can be difficult to prompt others to self-disclose because people often feel embarrassed disclosing personal matters to others. Although artificial agents without strong social pressure for listeners to induce self-disclosure is a promising engineering method that can be applied in daily stress management and reduce depression, gender difference is known to make a drastic difference of the attitude toward robots. We hypothesized that, as compared to men, women tend to prefer robots as a listener for their self-disclosure. The experimental results that are based on questionnaires and the actual self-disclosure behavior indicate that men preferred to self-disclose to the human listener, while women did not discriminate between robots and humans as listeners for their self-disclosure in the willingness and the amount of self-disclosure. This also suggests that the gender difference needs to be considered when robots are used as a self-disclosure listener.
\end{abstract}

Keywords: self-disclosure; gender difference; conversational robot

\section{Introduction}

Disclosing personal matters to other individuals often contributes to the maintenance of our mental health and social bonding. Many psychological studies have reported that sharing information about ourselves with other people is an effective way of managing stress [1,2] and building an intimate relationship [3,4]. It has also been reported that psychiatric symptoms, such as depression, can be reduced by disclosing one's serious problems [5-7]. Furthermore, neuroscientific findings support the effectiveness of self-disclosure as a source of pleasure and reward [8]. However, in face-to-face situations, it can be difficult to prompt others to self-disclose, because people often feel embarrassed disclosing personal matters to others $[9,10]$.

Using artificial agents for listeners to induce self-disclosure is a promising engineering method that can be applied in daily stress management and reduce depression. This is because their social pressure is lower than that of humans. Gratch et al. have developed a counseling system of display agents and reported that the resistance to self-disclosure is reduced when the users feel that the agents are not being manipulated by human operators [11]. There have been several innovative attempts to make physical robots ideal listeners to our serious worries without mental barriers. Uchida et al. [12] reported that people preferred to disclose negative topics to socialized robots (human-like android 
gendered as female and small robot) over human listener. They also suggested that the topics that people preferred to disclose varied across different types of robots, and it was also reported that the robot's self-disclosure encouraged reciprocal self-disclosure [13-15]. Furthermore, adults, with autism spectrum disorder (ASD), who have serious difficulties communicating also preferred to disclose about themselves to a robot listener rather than human listeners, especially on topics that may be embarrassing [16].

Although previous researches have primarily focused on methods used to design a robot's behavior to promote user's self-disclosure, there are few findings that focus on the human attitude toward robots. Especially, it is known that the attitude toward robots varies among genders. Osawa suggested that women tended to anthropomorphize robots in comparison with men [17]. Furthermore, Nomura et al. [18] reported that women tend to show a positive attitude toward anthropomorphic robots and Mumm et al. [19] suggested that physical distances between robots and women were less when compared to men. From this viewpoint, we hypothesized that women tend to prefer robots as a listener for their self-disclosure in comparison with men. Whereas, there are no integrated experimental findings exploring the interaction between the presence of a robot listener and the gender difference in self-disclosure.

In the context of self-disclosure, various properties, such as gender, age, and appearance in the listeners, should affect the result. To our knowledge, this study was the first case study that examined the gender difference in preference of self-disclosure for robots. Therefore, in this study, as a case report, Japanese female and gender-matched android were adopted as listeners for self-disclosure. Subsequently, we would like to argue the confirmed findings and the limitation of this case study at the discussion section. In this study, we mainly focused on the difference between genders with respect to the proportion and willingness of preferring a human or robot listener and its effect on self-disclosure. Previous study [12] have reported that the rate at which participants wanted to self-disclose to the robot depends on whether the content of self-disclosure was positive or negative. These attitudes were quantified based on subjective questionnaires, and the actual amount of self-disclosure expressed to each listener. From these investigations, we tried to verify the hypothesis that women, as compared to men, prefer to disclose themselves to robots. In this study, we focused on the selected rate of self-disclosure listener, willingness, and the amount of utterance of self-disclosure as dependent variables and compared these variables between men and women according to their listeners for verifying our hypothesis.

\section{Materials and Methods}

Our hypothesis is that women prefer to self-disclose to robot listeners in comparison with men. We examine two measurements to investigate this hypothesis, selected ratio of preferable listener (asked by a questionnaire) and actual number of utterances of self-disclosure measured by mora number. In addition to this basic analysis, we also asked participants about the impression of three types of listeners through a questionnaire, to verify whether the gender difference in self-disclosure to robots occur due to the difference in the impression on robots between women and men.

\subsection{Participants}

The purpose of this study is to conduct daily stress management. For this purpose, this experiment was conducted on healthy young Japanese people. During the recruitment process, we told the participants that the experiment uses robots. We did not inquire as to whether they had prior experience in interacting with robots. Participants' native language was Japanese and the age was limited to 18-30 years. In addition, we told the participants' that the self-disclosure data was used in an unidentified form 36 Japanese participants (17 women, 19 men, $18-28$ years old, $M=20.64, S D=1.96$ ) were recruited. The gender of participants was assessed by selecting one from male female options in the questionnaire. All of the participants gave their informed consent for inclusion before they 
participated in the study. The study was conducted in accordance with the Declaration of Helsinki, and the protocol was approved by the Ethics Committee of Osaka University, Japan.

\subsection{Materials}

As experimental conditions (within-participants design), we prepared three types of listeners for the participant's self-disclosure: a woman, two androids gendered as female (ERICA and Geminoid F), and one small robot. The human and robots only uttered pre-determined scripts. The timings of the robot's utterance and behavior were remotely controlled by the experimenter. The details of these listeners are described below.

\subsubsection{Human listener (Midori)}

Midori (confederate) is a Japanese female listener in her early thirties. Only a female listener was used to match the gender of the androids.

\subsubsection{Androids (ERICA and Geminoid F)}

As the human-like appearance of the androids include many parameters that should be controlled, the results may be biased and not generalized if we were to verify them with only one android. Therefore, we prepared two androids, ERICA and Geminoid F, in order to avoid the issue where our findings become specific to a particular android. ERICA and Geminoid F are androids gendered as female with a human-like appearance [20] (see ERICA: Figure 1a and Geminoid F: Figure 1b). As ERICA and Geminoid F speak, their lip movements, heads, and torsos are in sync with the prosodic features of their voice. These movements are automatically generated from their voice (using the systems developed by [21,22]). We used VOICE TEXT ERICA from the HOYA CORPORATION (http:/ / voicetext.jp/) to utter words via remote operation for both of the androids.

\subsubsection{Small Robot (CommU)}

CommU (Figure 1c) is a small humanoid robot with a little body that resembles a child. It is approximately $30 \mathrm{~cm}$ in height and it is equipped with speakers in the chest; it opens and closes its mouth when uttering words. We used AITalk (http://www.ai-j.jp/) to utter words via remote operation for the small robot.

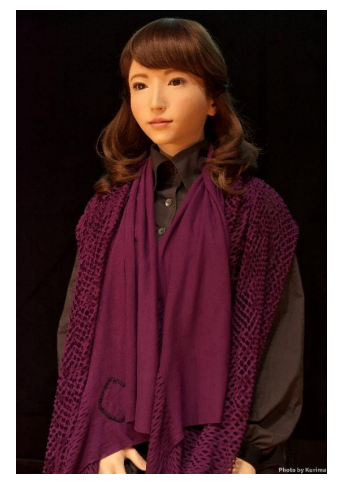

(a) ERICA

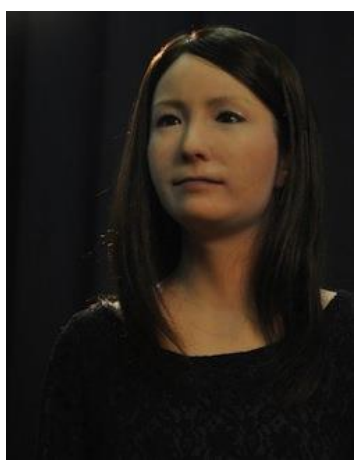

(b) Geminoid F

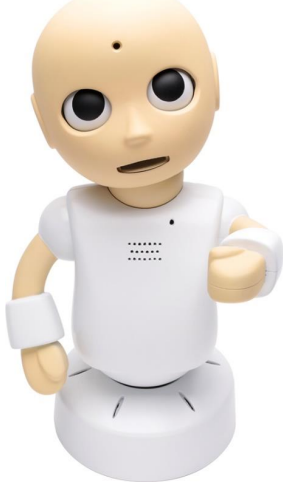

(c) CommU

Figure 1. Android and robot listeners.

\subsection{Procedure}

At the beginning of the experiment, each participant faced and greeted the three listeners (human, android, and robot) one-by-one in separate parts of the experiment room, as shown in Figure 2. The order of the greetings was randomized among participants. The listeners uttered the following scripts (Figure 3) for their greetings. 


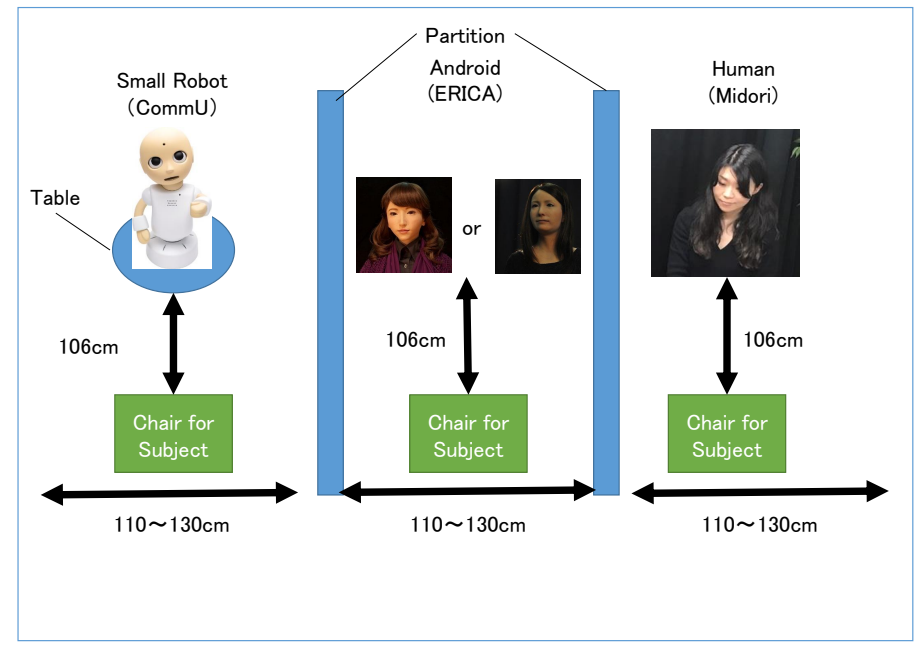

Figure 2. Experimental Settings.

Human: Nice to meet you. My name is Midori. Thank you very much. Android: Nice to meet you. My name is ERICA. Thank you very much. Small Robot: Nice to meet you. My name is CommU. Thank you very much.

Figure 3. Script of Greeting.

Immediately after each greeting, the participants evaluated their impressions of the listeners' kindness and feelings of intimidation using a four-point Likert scale questionnaire (0: none, 1: low, 2: high, 3: extremely high). The question of kindness was "How much kindness did you feel?" for each listener. The question of kindness was "How much feelings of intimidation did you feel?" for each listener. In addition, we also used the Inclusion of Other in the Self (IOS scale; Figure 4). In Figure 4, 7 means the self and the other is in close relationship, whereas 1 means the relationship is not close. This is an established measurement quantifying the intimacy between one's self and another party, in this case, the listener [23].

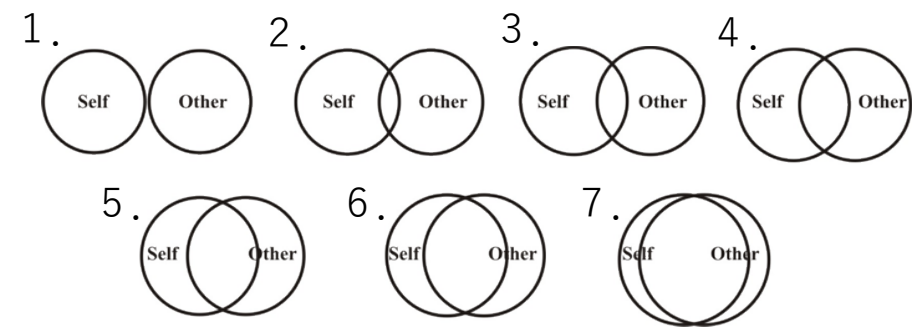

Figure 4. Representation of the IOS scale.

Once the participants had greeted all of the listeners, they moved to another room and were given a list of various topics for self-disclosure. We used 45 topics that are listed in the Enomoto Self-Disclosure Questionnaire-45 (ESDQ-45) [24], which are representative of the self-disclosure contents for the Japanese. For each topic, the participants were asked to select their preferred option for each of the three listeners (human, android, and small robot). The question was "Please choose the listener who is the easiest to talk about the topic". on each topic. Examples of the 45 topics are shown in Table 1. In addition, the participants were also asked to evaluate their willingness to self-disclose each topic using a seven-point Likert scale (1: Extremely willing to disclose and 7: Extremely unwilling to disclose). The question was "How willingly do you want to talk about the topic?" on each topic.

After the participants had completed the questionnaire, they were instructed to disclose several topics to each of the listeners face-to-face. The order of the disclosures was randomized among the 
participants, and the set up illustrated in Figure 2 was used. Six self-disclosure questions were randomly selected from ESDQ-45) [24] in advance. Table 1 shows the six self-disclosure topics. We assigned two of them randomly to each listener for each participants. Subsequently, each listener asked the participants to disclose information about the two topics. These topics were prepared independently from the questionnaire assessment before the actual self-disclosure session. The listeners informed the participant that they could refuse to answer the questions if a topic was too sensitive for them. The script is shown in Figure 5.

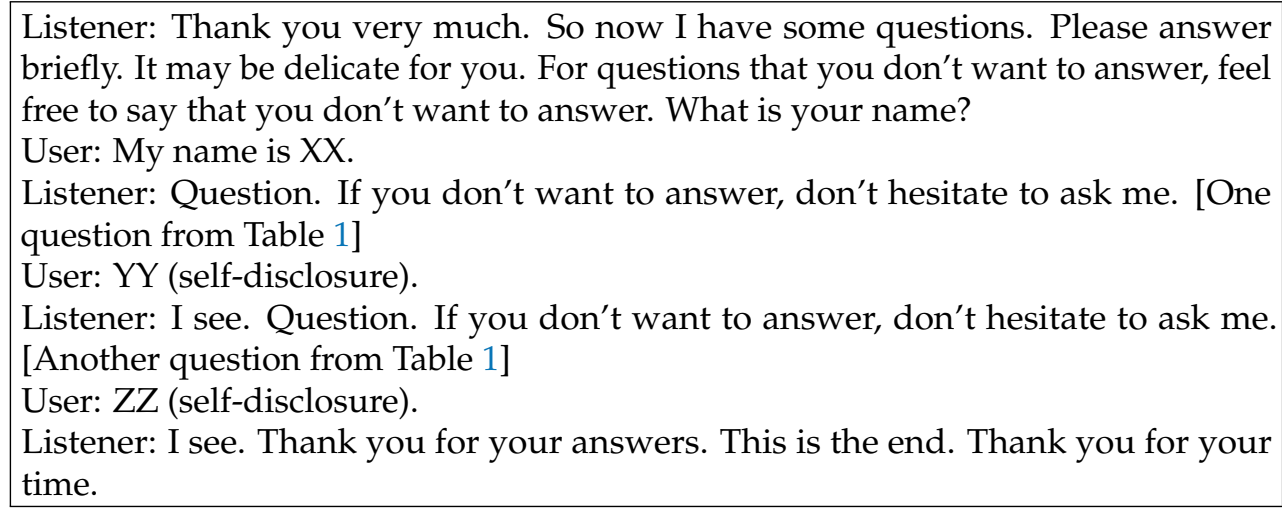

Figure 5. Script of Self-disclosure.

Table 1. Topics in actual self-disclosure experiment.

\begin{tabular}{ll}
\hline Negative Topic & $\begin{array}{c}\text { Positive Topic } \\
\text { Item }\end{array}$ \\
\hline $\begin{array}{l}\text { Opinions on recent major incidents } \\
\text { Experience of jealousy }\end{array}$ & $\begin{array}{l}\text { Professional/career interests } \\
\text { Dissatisfaction with and wishes for parents } \\
\text { Troubles in friendship }\end{array}$ \\
\hline
\end{tabular}

We evaluated the number of utterances of self-disclosure to the human and robot listeners. We quantified the amount of self-disclosures by counting the number of mora in Japanese; a mora determines syllable weight and it is a segmental unit of sound with a certain temporal length that is based on phonological theory [25].

\subsection{Pre-Investigation of Self-Disclosure Topics}

To label the positive/negative valences of the 45 self-disclosure topics, we performed a pre-assessment to quantify the degree to which a topic focuses on the positive side of life. 19 participants (11 men, eight women, $18-28$ years old, $M=22.47$, $S D=2.72$ ) who did not participate in the main experiment rated the degree of positivity for each topic in the questionnaire using a seven-point Likert scale. The results are shown in Table 2. To categorize the topics, we used the Ward method [26] (also called the minimum variance method), which is one of the standard clustering methods when considering the standard deviations of a dataset. Based on the degrees of positivity of each topic, we divided the topics into two categories. We defined the topics that scored highly as positive topics and those that scored poorly as negative topics. 
Table 2. Degree of positive/negative valence for each topic.

\begin{tabular}{|c|c|c|c|c|c|}
\hline Negative Group & \multicolumn{4}{|c|}{ Positive Group } & \multirow[b]{2}{*}{$S D$} \\
\hline Topic & Mean & $S D$ & Topic & Mean & \\
\hline (1) Confidence or anxiety about intellectual ability & 4.47 & 1.31 & (3) Goals you have now & 5.84 & 1.31 \\
\hline (2) Experience of being terribly hurt & 2.37 & 1.46 & (10) Use of inquiries & 5.84 & 0.99 \\
\hline (5) Athletic ability & 4.21 & 1.88 & (13) How to spend your holiday & 5.58 & 1.35 \\
\hline (6) Experience of sexual impulses & 4.11 & 1.41 & (14) Opinions on literature and art & 5.11 & 1.12 \\
\hline (7) What you like and dislike in friends & 2.90 & 1.84 & (16) Studying with interest & 6.11 & 0.97 \\
\hline (11) Parents' strengths and weaknesses & 4.26 & 2.00 & (25) Interior of my room & 5.21 & 1.28 \\
\hline (15) Friend's gossip story & 3.00 & 1.34 & (28) Information on entertainment and sports & 5.11 & 1.12 \\
\hline (17) What is emotional immaturity & 2.63 & 0.98 & (31) Intellectual interest & 5.42 & 1.53 \\
\hline (18) Values held & 4.37 & 1.81 & (33) Lifestyle goals/goals for lifestyle/ideal lifestyle & 6.21 & 0.77 \\
\hline (20) Constitutional problems & 2.89 & 1.29 & (40) Preferred clothing & 5.42 & 1.60 \\
\hline (21) Interest and troubles concerning gender & 3.89 & 1.68 & (43) Hobbies & 5.68 & 0.98 \\
\hline (29) Opinions on recent major incidents & 3.79 & 1.58 & & & \\
\hline (30) Gossip about celebrities & 3.21 & 1.28 & & & \\
\hline (32) Experience of jealousy & 2.47 & 1.35 & & & \\
\hline (34) Problems concerning appearance & 2.95 & 1.64 & & & \\
\hline (35) Personal health problems & 2.68 & 1.17 & & & \\
\hline (36) Interest and troubles concerning genitals & 3.32 & 1.62 & & & \\
\hline (37) Looking for friendship & 4.74 & 1.29 & & & \\
\hline (38) Feelings about opposite sex & 4.79 & 1.40 & & & \\
\hline (39) Position of work in life & 4.53 & 1.43 & & & \\
\hline (41) Dissatisfaction with and wishes for parents & 3.37 & 1.75 & & & \\
\hline (42) Loneliness and alienation & 2.00 & 0.92 & & & \\
\hline (44) Complaints and dissatisfaction with society & 2.58 & 1.39 & & & \\
\hline (45) Heterosexual gossip of interest & 3.79 & 1.28 & & & \\
\hline
\end{tabular}

\section{Results}

Our hypothesis was that women, as compared to men, prefer to disclose about themselves to robots. To verify it, we used three measurements: impression, selected rate, willingness, and the amount of self-disclosure. For impression and willingness, we used ANOVA since these are quantitative variables using the Likert method. For the selected rate, we used chi-square tests because the data is a qualitative variable of proportion. As for the amount of self-disclosure, we should use ANOVA because the amount of self-disclosure utterance is quantitative variable, but the amount may vary greatly between individuals, for example, those who are talkative or not. Therefore, we used a non-parametric test after standardization to remove the effect of individual differences.

In this experiment, we used two types of androids. First, we compared the results of the two androids (described in Appendix A). From the observations, it was clarified that the two androids results were not significantly different. Subsequently, the two androids' data were merged as one condition (i.e., an android condition). The results for verifying the hypothesis is explained as below.

\subsection{Impression of Listeners}

In this study, we evaluated three impression measurements (kindness, intimidation, and IOS scale) that considered related to self-disclosure. We used a two-way ANOVA to investigate whether there is a difference in these measurements between men and women according to listeners. It was conducted using kindness, intimidation, and IOS as the dependent variables, and gender and listeners as dependent variables. Table 3 shows the results for the three aspects of the participants' impression of the listeners.

Regarding the IOS scale, data for one male participant are missing due to problems in data transmission. Therefore, 35 participants (17 men, 18 women, $18-28$ years old, $M=20.66, S D=1.98$ ) evaluated the IOS scale for each listener. A two-way ANOVA revealed that the gender of the participant had no significant main effect $\left(F(1,33)=0.18, p=0.673, \eta^{2}=0.001\right)$, while the choice of listener had a significant main effect $\left(F(2,66)=17.80, p=0.0001, \eta^{2}=0.35\right)$. It also revealed that there was 
no significant interaction on gender $\times$ listener $\left(F(2,66)=0.02, p=0.98, \eta^{2}=0.001\right)$. A post-hoc test (Bonferroni method) revealed that the score for the human condition $(M=3.20, S D=1.39)$ was significantly higher than those for the android $(M=1.97, S D=1.08)(p=0.0001)$ and small robot $(M=1.60, S D=1.07)(p=0.0001)$ conditions.

Table 3. Participants' impression of the listeners.

\begin{tabular}{llcccccc}
\hline \multirow{2}{*}{ Impression Item } & Gender & \multicolumn{2}{c}{$\begin{array}{c}\text { Human } \\
\text { Mean }(S D)\end{array}$} & \multicolumn{3}{c}{$\begin{array}{c}\text { Android } \\
\text { Mean }(S D)\end{array}$} & \multicolumn{3}{c}{$\begin{array}{c}\text { Small Robot } \\
\text { Mean (SD) }\end{array}$} \\
\hline \multirow{2}{*}{ IOS } & Male & 3.17 & $(1.46)$ & 1.89 & $(1.15)$ & 1.56 & $(0.83)$ \\
& Female & 3.24 & $(1.31)$ & 2.06 & $(1.00)$ & 1.65 & $(1.28)$ \\
\hline \multirow{2}{*}{ Kindness } & Male & 1.68 & $(0.92)$ & 0.74 & $(0.71)$ & 0.58 & $(0.67)$ \\
& Female & 2.06 & $(0.80)$ & 1.53 & $(0.78)$ & 0.71 & $(0.75)$ \\
\hline \multirow{2}{*}{ Intimidation } & Male & 0.26 & $(0.44)$ & 1.2 & $(0.83)$ & 0.26 & $(0.55)$ \\
& Female & 0.35 & $(0.48)$ & 1.12 & $(0.76)$ & 0.53 & $(0.61)$ \\
\hline
\end{tabular}

Regarding kindness, a two-way ANOVA revealed that the gender of the participant and the choice of listener both had significant main effects $\left(F(1,34)=5.97, p=0.020, \eta^{2}=0.07\right)$ and $(F(2,68)=$ $\left.25.51, p=0.0001, \eta^{2}=0.39\right)$, respectively. It also revealed that there was no significant interaction on gender $\times$ listener $\left(F(2,68)=1.89, p=0.16, \eta^{2}=0.03\right)$. A post-hoc test (Bonferroni method) revealed that the score for the human condition $(M=1.86, S D=0.89)$ was significantly higher than those for the android $(M=1.11, S D=0.84)(p=0.001)$ and small $\operatorname{robot}(M=0.64, S D=0.71)(p=0.0001)$ conditions. It was also revealed that the score for the android condition was significantly higher than that for the small robot condition $(p=0.009)$.

Regarding intimidation, a two-way ANOVA revealed that the gender of the participant had no significant main effect $\left(F(1,34)=0.37, p=0.55, \eta^{2}=0.01\right)$ and that the choice of listener had a significant main effect $\left(F(2,68)=23.34, p=0.0001, \eta^{2}=0.41\right)$. It also revealed that there was no significant interaction on gender $\times$ listener $\left(F(2,68)=0.85, p=0.43, \eta^{2}=0.02\right)$. A post-hoc test (Bonferroni method) revealed that the score for the android condition $(M=1.17, S D=0.80)$ was significantly higher than the scores for the human $(M=0.31, S D=0.46)(p=0.0001)$ and small robot $(M=0.39, S D=0.59)(p=0.0001)$ conditions.

\subsection{Selected Rates of Preferred Listeners for Positive/Negative Topics}

Here, we evaluated the rate selected as a listener for each topic of self-disclosure. Since a previous study [12] reported that self-disclosure to robots differs depending on the positive or negative topics, we conducted the analysis of the selected rate in positive or negative of the topic category, respectively. We used a chi-squared test to investigate whether there is a difference in the selected rate between men and women according to listeners. It was conducted using the selected rate on positive/negative topics as the dependent variable, and gender and listeners as dependent variable.

Table 4 shows the result of the selected rate of each self-disclosure listener. In the negative topic, the gender $\times$ listener $\chi^{2}$-test revealed that there was significant effect $\left(\chi^{2}(2)=23.41, p=0.001, \phi=0.15\right)$. A residual analysis indicated that the adjusted residual of the human condition was 4.80, the android condition was -2.70 , and the small robot condition was -2.90 in the male group. It also indicated that the adjusted residual of the human condition was -4.80 , the android condition was 2.70 , and the small robot condition was 2.90 in the female group. From the results, it was clarified that the human was selected significantly higher $(p<0.001)$ in the male group, while the android was significantly higher $(p<0.01)$ in the female group.

In the positive topics, the gender $\times$ listener $\chi^{2}$-test revealed that there was significant effect $\left(\chi^{2}(2)=47.17, p=0.001, \phi=0.31\right)$. A residual analysis indicated that the adjusted residual of the human condition was 6.70 , the android condition was -3.00 , and the small robot condition was -5.20 in the male participants. It also indicated that the adjusted residual of the human condition was -6.70 , 
the android condition was 3.00, and the small robot condition was 5.20 in the female group. From the results, it was clarified that the human was selected significantly higher $(p<0.001)$ in the male participants, while the android $(p<0.01)$ and small robot $(p<0.001)$ were significantly higher in the female participants.

Table 4. Participant's preference of self-disclosure listener $\left.{ }^{* *}: p<0.01\right)$.

\begin{tabular}{llrrrrrr}
\hline \multirow{2}{*}{ Topic } & Gender & \multicolumn{2}{c}{$\begin{array}{c}\text { Human } \\
\text { Mean }(S D)\end{array}$} & \multicolumn{2}{c}{$\begin{array}{c}\text { Android } \\
\text { Mean }(S D)\end{array}$} & \multicolumn{2}{c}{$\begin{array}{c}\text { Small Robot } \\
\text { Mean }(S D)\end{array}$} \\
\hline \multirow{2}{*}{ Negative } & Male & $0.59^{* *}$ & $(0.11)$ & 0.19 & $(0.09)$ & 0.22 & $(0.09)$ \\
& Female & 0.45 & $(0.12)$ & $0.26^{* *}$ & $(0.11)$ & 0.30 & $(0.11)$ \\
\hline \multirow{2}{*}{ Positive } & Male & $0.72^{* *}$ & $(0.10)$ & 0.18 & $(0.09)$ & 0.11 & $(0.07)$ \\
& Female & 0.42 & $(0.12)$ & $0.29^{* *}$ & $(0.11)$ & $0.29^{* *}$ & $(0.11)$ \\
\hline
\end{tabular}

\subsection{Willingness to Self-Disclose}

In this experiment, the participants selected one of the three (i.e., human, android, small robot) for self-disclosure listener. Here, in some topics, they might unwillingly select one listener though they did not want to self-disclose them to any listener. Therefore, we analyze the evaluation of the degree to which they want to talk about each topic. We scored it as the listener's score on each topic. We used a two-way ANOVA to investigate whether there is a difference in the willingness between men and women. It was conducted using the willingness on positive/negative topics as the dependent variable, and gender and listeners as dependent variable. In the analysis, we score -3 to 3 , which is compatible with 1 to 7 in the questionnaire.

Figure 6a shows the mean score for the degree of willingness to disclose negative content when each listener was selected as the self-disclosure listener. On the negative topic, a two-way ANOVA (gender $\times$ listener) revealed that there was no significant main effect on gender of the participants $\left(F(1,1110)=2.35, p=0.13, \eta^{2}=0.002\right)$, while there was a significant main effect on the listener $\left(F(2,1110)=16.00, p=0.0001, \eta^{2}=0.03\right)$. It also revealed that there was significant (gender of participant $\times$ listener $)$ interaction $\left(F(2,1110)=5.66, p=0.004, \eta^{2}=0.01\right)$. A post-hoc test revealed that there was significant difference among gender in the human condition $(p=0.0001)$, while there were no significant differences among gender in the android condition $(p=0.16)$ and the small robot condition $(p=0.12)$. Among the male participants, a post-hoc test (Bonferroni method) revealed that there were significant differences between the human and the small robot conditions $(p=0.0001)$ and the android and the small robot conditions $(p=0.001)$, while there were no significant differences between the human and the android conditions $(p=0.28)$. Among the female participants, a post-hoc test (Bonferroni method) revealed that there were no significant differences between the human and the android conditions ( $p=1.000)$, the human and small robot conditions $(p=0.31)$, and the android and small robot conditions $(p=1.000)$.

Figure $6 \mathrm{~b}$ shows the mean score for the degree of willingness to disclose positive content when each listener was selected as the preferred listener. In the positive topic, a two-way (gender $\times$ listener) ANOVA revealed that there was a significant main effect on listener $\left(F(2,498)=6.54, p=0.002, \eta^{2}=\right.$ 0.03 ) and no significant main effect on gender $\left(F(1,498)=0.006, p=0.94, \eta^{2}=0.0001\right)$. It also revealed that there was significant gender $\times$ listener interaction $\left(F(2,498)=3.66, p=0.03, \eta^{2}=0.01\right)$. A post-hoc test revealed that there was a significant difference between gender in the human condition $(p=0.04)$, while there were no significant differences between genders in the android $(p=0.44)$ and small robot ( $p=0.06)$ conditions. In the male participants, a post-hoc test (Bonferroni method) also revealed that there were significant differences between the human and the small robot conditions $(p=0.0001)$, while there were no significant differences between the human and the android conditions $(p=0.18)$ and the android and the small robot conditions $(p=0.16)$. In the female participants, a post-hoc test (Bonferroni method) revealed that there were no significant differences between the 
human and the android conditions $(p=0.64)$, the human and small robot conditions $(p=1.000)$, and the android and small robot conditions $(p=1.000)$.

These results suggest that the male participants actively select the human listener as self-disclosure listener, while the female participants had no bias for the willingness for self-disclosure by listeners.

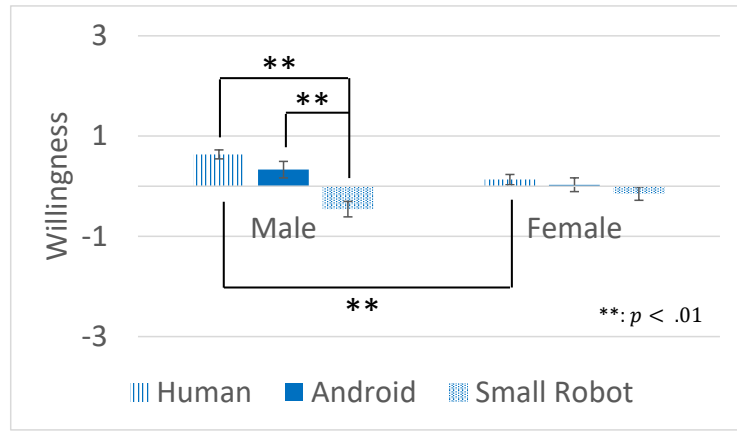

(a) Negative topic

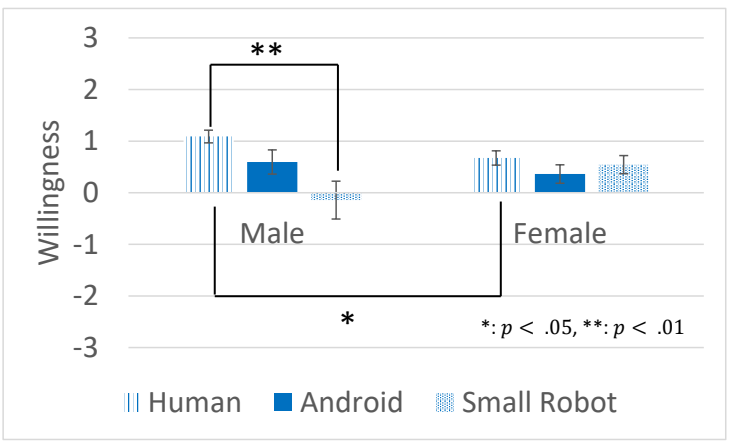

(b) Positive topic

Figure 6. Willingness to self-disclose (The error bars show the standard errors).

\subsection{Amount of Actual Self-Disclosure}

In the last part of the experiment, the participants actually disclosed information regarding some topics to each listener. Here, we evaluate the actual amount of self-disclosure. An ANOVA should be used because the amount of utterance is a quantitative variable. However, the amount of self-disclosure may vary greatly between individuals, for example, those who are talkative or not. Therefore, after standardization with Z-scores to remove the effect of individual differences, we used a non-parametric test to investigate whether there is a difference in the amount of self-disclosure between men and women. It was conducted using Z-score of the self-disclosure utterances in response to the self-disclosure question as dependent variable, and gender and listeners as the dependent variable. To analyze the self-disclosure utterances of the participant, we calculated the number of mora in the utterances. The participants were told that they do not have to answer if they did not want to. In that case, we assumed that they made no utterance for self-disclosure, and set the number of mora to zero.

Figure 7 shows the mean $\mathrm{Z}$ score. A Mann-Whitney U test indicated that there was significant difference among gender in the human condition $(p=0.04)$, while there were no significant differences among gender in the android $(p=0.06)$ and the small robot $(p=0.57)$ conditions.

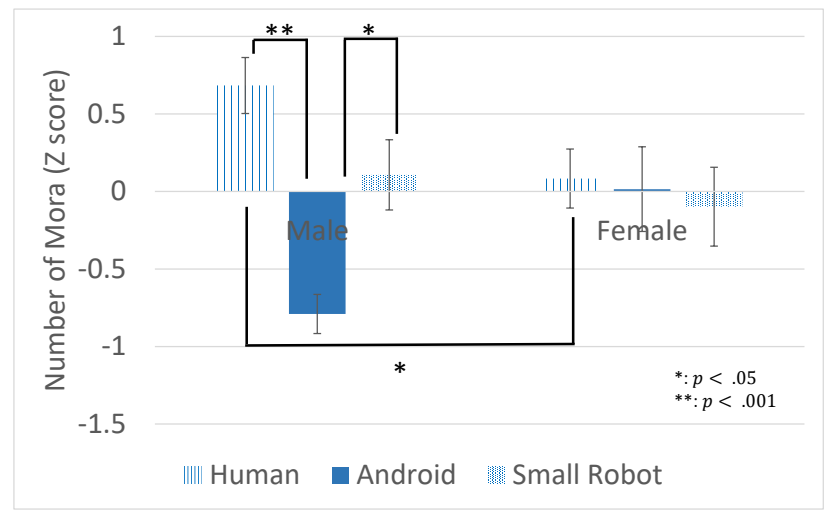

Figure 7. Amount of self-disclosure (The error bars show the standard errors). 
In the male group, a Friedman test revealed that there was a significant main effect $\left(\chi^{2}(2)=\right.$ 9.36, $p=0.009)$. A Wilcoxon signed-rank test revealed that there were significant differences between the human and the android condition $(p=0.0001)$, and the android and small robot condition $(p=0.020)$, while there were no significant differences between the human and the small robot conditions $(p=0.21)$. In the female group, a Friedman test revealed that there was a significant main effect $\left(\chi^{2}(2)=0.09, p=0.96\right)$.

The results of the amount of self-disclosure suggest that the male participants self-disclose more to the human listener compared with the female participants. In addition, the male participants self-disclose less to the androids when compared to the human listener and the small robot.

Finally, we computed the correlation to investigate the type of index that is related to the actual self-disclosure. Table 5 shows Spearman's rank correlation coefficient $\left(r_{s}\right)$ between the amount of self-disclosure and the questionnaire items.

Table 5. Correlation coefficient between amount of self-disclosure and questionnaire items $\left(^{*}: p<0.05,{ }^{* *}: p<0.01\right)$.

\begin{tabular}{|c|c|c|c|c|c|c|c|}
\hline \multicolumn{2}{|c|}{ Item } & \multicolumn{2}{|c|}{$\begin{array}{c}\text { Male } \\
r_{s}(p \text {-Value })\end{array}$} & \multicolumn{2}{|c|}{$\begin{array}{c}\text { Female } \\
r_{s}(p)\end{array}$} & \multicolumn{2}{|c|}{$\begin{array}{l}\text { Total } \\
r_{s}(p)\end{array}$} \\
\hline \multirow{3}{*}{ Impression } & IOS & .26 & $(0.06)$ & 0.04 & $(0.78)$ & 0.19 & $(0.05)$ \\
\hline & Kindness & 0.15 & $(0.28)$ & 0.11 & $(0.44)$ & 0.12 & $(0.22)$ \\
\hline & Intimidation & -0.29 * & $(0.03)$ & -0.13 & $(0.37)$ & -0.22 * & $(0.02)$ \\
\hline \multicolumn{2}{|l|}{ Selected rate } & $0.42 * *$ & $(0.001)$ & .16 & $(0.27)$ & $0.30 * *$ & $(0.002)$ \\
\hline \multicolumn{2}{|l|}{ Willingness } & $0.44^{* *}$ & $(0.002)$ & .19 & $(0.21)$ & $0.29^{* *}$ & $(0.004)$ \\
\hline
\end{tabular}

The result of the correlation indicates that the intimidation is negatively correlated with the amount of self-disclosure among the male participants. Furthermore, the selected rate and willingness are positively correlated with the amount of self-disclosure in the male group.

\section{Discussion}

In this study, we conducted an experiment to verify the hypothesis that women, as compared to men, prefer to self-disclose to robots. The experimental results show that the female participants tend to self-disclose to robots more than the male participants, regardless of positive/negative topics. Furthermore, female participants tended not to discriminate positive/negative topics in self-disclosure to robots, whereas male participants preferred to disclose to the human listener. The previous findings reported in Uchida et al. [12] that a preference to select robot listeners for negative topics was seen among the male participants. Our findings suggest that gender difference is a considerable factor for promoting human self-disclosure while using robot listeners.

There are two interpretations from our results. One is that participants merely selected robot listeners, because they did not prefer to openly discuss their feelings with a strange human listener. This interpretation is the passive reason for disclosing to a robot. The other interpretation is that participants had active reasons for selecting robot listeners instead of the human. To clarify this point, we compared the scores of "willingness" between the topics selected to talk to humans and those selected to talk to robots. The result showed that the mean of willingness score of topics for the human listener was significantly higher than that for robot listeners among the ale participants. In contrast, there was no difference among female participants. Therefore, in female participants, it could be said that the robot listener was not selected according to passive reasons, whereas male participants may utilize robot listeners to avoid disclosing negative topics to a human listener.

One of the interesting points of our study is that we evaluated self-disclosure toward robots by using both subjective measurements and actual utterance of self-disclosure. Consequently, we could find a similar gender difference, even in the number of self-disclosure utterances to robots. Specifically, the amount of self-disclosure toward robots are relatively smaller than that toward the human listener 
among male participants; whereas, the amount of self-disclosure in female participants was equally distributed. Furthermore, there are some significant correlations between subjective impressions and the amount of actual utterances of self-disclosure among male participants. On the other hand, there are no significant correlations among female participants. This might indicate the gender difference in the cognitive process for self-disclosure. A previous study of social psychology suggested that male participants were sensitive to the immediate impression of the other agent, in comparison with female participants, in a social situation [27]. From this finding, we speculated that male participants might eagerly utilize the subjective (explicit) impression when they judged whether or not a listener agent was appropriate for their self-disclosure. Meanwhile, female participants may judge an appropriate listener for self-disclosure by accessing more intuitive processes that were not reflected in the one-shot questionnaire. This interpretation is speculative, and we must verify this speculation by performing further experiments.

There are many other considerable factors that may explain the gender differences that were observed in our experiment. Osawa et al. [17] had reported that women tend to anthropomorphize artificial agent in comparison with men. This psychological trait of female gender might weaken the border between human and robot listeners in self-disclosure. Meanwhile, based on a previous study [16], anthropomorphism does not always promotes self-disclosure. Sometimes non-human-like small robot promoted human self-disclosure rather than human-like android. Hence, further investigations of the relationship between anthropomorphism and self-disclosure were required. Generally, it is known that the tendency of self-disclosure toward human listeners also differ between female and male genders [28]. Furthermore, it was also suggested that this gender difference in self-disclosure might be caused by the expected social roles [29]. We believe that the differences in gender may be due to social role theory [30], rather than biological difference, and we need to examine this point in the future. Hence, the attitude difference in the self-disclosure toward robot listeners may also be caused by the expected social roles of women in the Japanese culture. One reason why women preferred to select robot listeners might be caused by the absence of communities where female people can disclose about themselves without worrying because of expected social roles for females [31]. Of course, we should not argue the effect of gender simply, because the amount of individual difference exists, even in the same gender. Hence, we must manipulate the social roles and personality of the participants as depending variables in future experiments. Regarding the result that has a significant difference with the small effect size, there may be other factors (e.g., personality) that are not limited to gender. Moreover, in this experiment, all of the participants were Japanese. Therefore, we must also consider cultural differences of our findings, because the expected gender roles differ between cultures [32,33].

\subsection{Limitation and Future Work}

In this study, we prepared three types of listener agents for self-disclosure. Each one represented a specific category of the listener agent (e.g., human, Android). However, this categorization is subjective, and the results obtained from a specific agent of a certain category cannot be generalized to be the same for all the other agents belonging to the same category. For example, there are many types of androids identified as belonging to the "android" category. However, their appearances and gender are different, and this diversity in the appearance within the "android" category may cause differences in the results. To mitigate the effects of the android's appearance as much as possible, we used two different androids with different visual appearances. Whereas, in the current study,we only use androids gendered as "female". This is one of critical limitations left on our current experimental design. For example, male participants might simply prefer to self-disclose to the female listener, regardless of whether the listener was human or robot. Although the results toward the small robot also differed between the male and female participants, we could not conclude that all of the results were caused by the difference in whether the listener is a robot or a human. In future investigations, we need to adopt androids gendered to be men. Likewise, we must also consider the diversity (e.g., gender, politeness, 
and presence of a unique name [34]) of "human" and "small robot" categories, and we would like to generalize the different features of the listener agents that would affect our self-disclosure. For example, previous studies on self-disclosure have reported that people of the same gender self-disclose more than people of the opposite gender [28]. On the other hand, only female androids were used in the current study, and we cannot verify whether male and female participants self-disclose in the same way to male androids. We would like to consider these points in the future.

Previous findings have suggested that building an intimate relationship between a speaker and listener is significantly important in self-disclosure [3,4]. However, our current study only focuses on the visual appearance of the listener agent, and we did not consider building rapport between the speaker and listener. This is a limitation in our study, and we should consider the ways to build a good relationship between humans and robots throughout the interactions. Arroyo et al. [35] have investigated the ways listener robots gain trust and relationships through interactions. Kanda et al. [14] have reported that long-term interaction can be stimulated by self-disclosure of the robot itself. These strategies will make robots good listeners for human self-disclosures.

One of the primary reasons for using robots as listeners for self-disclosure is that a robot does not belong within the human society, and it can be trusted to keep secrets. It has been reported that people may willingly adjust their behaviors more for overhearers than for their direct addressees [36,37]. In the setting of the previous study focusing on "overhears effect", the existence of bystanders were implied apparently (for example, the media talk or broadcast talk in the paper of [37]). Whereas, in our experiment, the area of the participants during self-disclosure was divided by separators (see Figure 2), in order to prevent the participants from being aware of the existence of bystanders. However, in reality, the high confidentiality is not guaranteed. There are no evidences that the experimenters did not hear the participants' self-disclosure through recordings of the participants' utterances. A sense that participant's self-disclosure was not revealed to others was necessary to strengthen the advantages of self-disclosing to robots.

In this study, the situation of self-disclosure was experimental, and it was not a natural situation. The participants were instructed to self-disclose as a required task in the laboratory environment. In the laboratory setting, participants often tend to pretend to be "a good subject" while being cautious toward the eyes of the experimenters [38,39]. Hence, there is a possibility that participants did not self-disclose true information in the laboratory setting. Although the laboratory setting is necessary to extract meaningful variables that are related to self-disclosure to robots, if we would like to investigate spontaneous (not instructed) self-disclosure to robots, we must install robot listeners in natural day-to-day settings and observe the natural behaviors of the participants [14]. Furthermore, in this study, we only focused on the quantitative measurement, the number of mora, for the analysis of actual self-disclosure because the content and amount of self-disclosure varied among participants. In the future, we would like to perform qualitative analysis for self-disclosure by refining the experimental setting.

Author Contributions: Conceptualization, T.U., H.T. and M.B.; methodology, T.U., H.T. and M.B.; software, T.U., H.T., J.S., T.M. and K.O.; validation, T.U., H.T. and M.B.; formal analysis, T.U., H.T. and M.B.; investigation, T.U., H.T. and M.B.; resources, T.U., H.T., M.B., J.S., T.M., K.O., Y.Y. and H.I.; data curation, T.U., H.T. and M.B.; writing-original draft preparation, T.U., H.T. and M.B.; writing-review and editing, T.U., H.T. and M.B.; visualization, T.U., H.T. and M.B.; supervision, T.M., Y.Y. and H.I.; project administration, H.T. and H.I.; funding acquisition, H.T. and H.I. All authors have read and agreed to the published version of the manuscript.

Funding: This research was funded by Japan Science and Technology Agency (JST), the Exploratory Research for Advanced Technology (ERATO), the ISHIGURO symbiotic human-robot interaction project (JPMJER1401), and Japanese Ministry of Education, Culture, Sports, Science, and Technology (MEXT). Grant-in-Aid for Scientific Research on Innovative Areas "Cognitive Interaction Design, A Model-based Understanding of Communication and its Application to Artifact Design (No. 4601)" (No. 15H01618).

Conflicts of Interest: The authors declare no conflict of interest. The funders had no role in the design of the study; in the collection, analyses, or interpretation of data; in the writing of the manuscript, or in the decision to publish the results. 


\section{Appendix A. Comparison between Two Different Androids}

In this experiment, we used two types of androids: ERICA and Geminoid F. We analyzed the difference between the two androids in each evaluation. 17 participants ( 9 men, 8 women, 18-24 years old, $M=20.47, S D=1.72$ ) participated in the experiment using ERICA, and 19 participants (10 men, 9 women, $18-28$ years old, $M=20.79, S D=2.14$ ) participated in the experiment using Geminoid F. Table A1 shows the results (Mean and SD) of each android. The following is the detailed results for comparing the two androids.

Table A1. Result of each android.

\begin{tabular}{|c|c|c|c|c|c|}
\hline \multicolumn{2}{|l|}{ Item } & \multicolumn{2}{|c|}{$\begin{array}{c}\text { ERICA } \\
\text { Mean (SD) }\end{array}$} & \multicolumn{2}{|c|}{$\begin{array}{c}\text { Geminoid F } \\
\text { Mean (SD) }\end{array}$} \\
\hline \multirow{3}{*}{ Impression evaluation } & IOS & 3.06 & $(1.51)$ & 3.33 & $(1.25)$ \\
\hline & Kindness & 1.18 & $(0.86)$ & 1.05 & $(0.83)$ \\
\hline & Intimidation & 1.18 & $(0.92)$ & 1.16 & $(0.67)$ \\
\hline \multirow{2}{*}{ Selected rate } & Negative topic & 0.20 & $(0.40)$ & 0.24 & $\begin{array}{l}(0.43) \\
\end{array}$ \\
\hline & Positive topic & 0.17 & $(0.38)$ & 0.28 & $(0.45)$ \\
\hline \multirow{2}{*}{ Willingness } & Negative topic & 0.20 & $(0.40)$ & 0.24 & $(0.43)$ \\
\hline & Positive topic & 0.17 & $(0.38)$ & 0.28 & $(0.45)$ \\
\hline
\end{tabular}

\section{Appendix A.1. Impression Evaluation}

Regarding the IOS scale, data for one male participant is missing due to problems in data transmission. 17 participants ( 9 men, 8 women, $18-24$ years old, $M=20.47, S D=1.72$ ) participated in the experiment using ERICA, and 18 participants (9 men, 9 women, $18-28$ years old, $M=20.83$, $S D=2.19$ ) participated in the experiment using Geminoid F. A two-way (type of android $\times$ gender of participant) ANOVA revealed that there were no significant main effects on the type of the androids $\left(F(1,31)=0.24, p=0.62, \eta^{2}=0.01\right)$ and the gender of the participants $\left(F(1,31)=0.24, p=0.62, \eta^{2}=\right.$ $0.01)$. It also revealed that there was no significant android type $\times$ gender of participant interaction $\left(F(1,31)=1.17, p=0.29, \eta^{2}=0.04\right)$.

Regarding kindness, a two-way (type of android $\times$ gender of participant) ANOVA revealed that there were no significant main effects on the type of the androids $\left(F(1,32)=0.30, p=0.59, \eta^{2}=0.01\right)$, while there was a significant main effect on the gender of the participants $(F(1,32)=9.79, p=$ $\left.0.004, \eta^{2}=0.23\right)$. It also revealed that there was no significant type of android $\times$ gender of participant interaction $\left(F(1,32)=1.13, p=0.30, \eta^{2}=0.03\right)$.

Regarding intimidation, a two-way (type of android $\times$ gender of participant) ANOVA revealed that there were no significant main effects on the type of the androids $\left(F(1,32)=0.004, p=0.95, \eta^{2}=0.001\right)$ and the gender of the participants $\left(F(1,32)=0.11, p=0.74, \eta^{2}=0.001\right)$. It also revealed that there was no significant android type $\times$ gender interaction $\left(F(1,31)=0.0001, p=0.99, \eta^{2}=0.001\right)$.

These results indicate that the impression of each android did not differ significantly.

\section{Appendix A.2. Selected Rate}

We calculated the selected rate of preferred listener for the android for each participant.

On the negative topics, a two-way (type of android $\times$ gender of participant) ANOVA revealed that there were no significant main effects on the type of the androids $\left(F(1,32)=0.34, p=0.57, \eta^{2}=0.01\right)$ and gender of the participants $\left(F(1,32)=1.03, p=0.32, \eta^{2}=0.03\right)$. It also revealed that there was no significant type of android $\times$ gender of participant interaction $\left(F(1,32)=0.22, p=0.64, \eta^{2}=0.007\right)$.

On the positive topics, a two-way (type of android $\times$ gender of participant) ANOVA revealed that there were no significant main effects on the type of the androids $\left(F(1,32)=3.85, p=0.06, \eta^{2}=0.10\right)$ and gender of the participants $\left(F(1,32)=3.6, p=0.07 ., \eta^{2}=0.09\right)$. It also revealed that there was no significant type of android $\times$ gender of participant interaction $\left(F(1,32)=1.23, p=0.28, \eta^{2}=0.04\right)$. 
These results indicate that the selected rate of each android did not differ significantly.

\section{Appendix A.3. Willingness for Self-Disclosure}

We calculated the participants' willingness for self-disclosure to the androids.

On the negative topics, a two-way (type of android $\times$ gender of participant) ANOVA revealed that there were no significant main effects on the type of the androids $\left(F(1,244)=0.52, p=0.47, \eta^{2}=0.001\right)$ and gender of the participants $\left(F(1,244)=1.56, p=0.21, \eta^{2}=0.01\right)$. It also revealed that there was no significant type of android $\times$ gender of participant interaction $\left(F(1,244)=0.56, p=0.46, \eta^{2}=0.001\right)$.

On the positive topics, a two-way (type of android $\times$ gender of participant) ANOVA revealed that there were no significant main effects on the type of the androids $\left(F(1,112)=1.38, p=0.24, \eta^{2}=0.01\right)$, and gender of the participants $\left(F(1,112)=0.13, p=0.72, \eta^{2}=0.007\right)$. It also revealed that there was no significant type of android $\times$ gender of participant interaction $\left(F(1,112)=3.40, p=0.07, \eta^{2}=0.03\right)$.

These results indicate that the willingness of the participants for each android did not differ significantly.

\section{Appendix A.4. Amount of Self-Disclosure}

The degree of talkativeness is considered to vary from participant to participant; the relativization of the amount of self-disclosure is necessary. To relativize the participant's amount of self-disclosure (i.e., the number of mora), we standardized it by each participant using a Z-score. Among the male participants, a Mann-Whitney $U$ test revealed that there was no significant difference between the androids' $Z$ score $(U=40.00, p=0.68, r=-0.09)$. Among the female participants, it also revealed that there was no significant difference between the androids' $\mathrm{Z}$ score $(U=22.00, p=0.18, r=-0.33)$.

These results indicate that the amount of self-disclosure to each android did not differ significantly.

\section{References}

1. Jourard, S.M. Self-Disclosure: An Experimental Analysis of the Transparent Self; Wiley-Interscience: Hoboken, NJ, USA, 1971.

2. Cozby, P.C. Self-disclosure: A literature review. Psychol. Bull. 1973, 79, 73. [CrossRef] [PubMed]

3. Collins, N.L.; Miller, L.C. Self-disclosure and liking: A meta-analytic review. Psychol. Bull. 1994, $116,457$. [CrossRef] [PubMed]

4. Dindia, K.; Allen, M.; Preiss, R.; Gayle, B.; Burrell, N. Self-disclosure research: Knowledge through meta-analysis. In Interpersonal Communication Research: Advances through Meta-Analysis; Routledge: Abingdon-on-Thames, UK, 2002; pp. 169-185.

5. Cohen, S.; Wills, T.A. Stress, social support, and the buffering hypothesis. Psychol. Bull. 1985, 98, 310. [CrossRef] [PubMed]

6. Pennebaker, J.W.; Beall, S.K. Confronting a traumatic event: Toward an understanding of inhibition and disease. J. Abnorm. Psychol. 1986, 95, 274. [CrossRef]

7. Silver, R.L. Coping with undesirable life events. In Human Helplessness: Theory and Applications; Academic: Amsterdam, The Netherlands, 1980.

8. Tamir, D.I.; Mitchell, J.P. Disclosing information about the self is intrinsically rewarding. Proc. Natl. Acad. Sci. USA 2012, 109, 8038-8043. [CrossRef]

9. Farber, B.A. Patient self-disclosure: A review of the research. J. Clin. Psychol. 2003, 59, 589-600. [CrossRef]

10. Farber, B.A. Self-Disclosure in Psychotherapy; Guilford Press: New York, NY, USA, 2006.

11. Gratch, J.; Lucas, G.M.; King, A.A.; Morency, L.P. It's only a computer: The impact of human-agent interaction in clinical interviews. In Proceedings of the 2014 International Conference on Autonomous Agents and Multi-Agent Systems, Paris, France, 5-9 May 2014; International Foundation for Autonomous Agents and Multiagent Systems: Richland, SC, USA; pp. 85-92.

12. Uchida, T.; Takahashi, H.; Ban, M.; Shimaya, J.; Yoshikawa, Y.; Ishiguro, H. A robot counseling system-What kinds of topics do we prefer to disclose to robots? In Proceedings of the 2017 26th IEEE International Symposium on Robot and Human Interactive Communication (RO-MAN), Lisbon, Portugal, 28 August-1 September 2017; pp. 207-212. 
13. Kanda, T.; Hirano, T.; Eaton, D.; Ishiguro, H. Interactive robots as social partners and peer tutors for children: A field trial. Hum. Interact. 2004, 19, 61-84. [CrossRef]

14. Kanda, T.; Sato, R.; Saiwaki, N.; Ishiguro, H. A two-month field trial in an elementary school for long-term human-robot interaction. IEEE Trans. Robot. 2007, 23, 962-971. [CrossRef]

15. Shiomi, M.; Kanda, T.; Howley, I.; Hayashi, K.; Hagita, N. Can a social robot stimulate science curiosity in classrooms? Int. J. Soc. Robot. 2015, 7, 641-652. [CrossRef]

16. Kumazaki, H.; Warren, Z.; Swanson, A.; Yoshikawa, Y.; Matsumoto, Y.; Takahashi, H.; Sarkar, N.; Ishiguro, H.; Mimura, M.; Minabe, Y.; et al. Can robotic systems promote self-disclosure in adolescents with autism spectrum disorder? A pilot study. Front. Psychiatry 2018, 9, 36. [CrossRef]

17. Osawa, H.; Mukai, J.; Imai, M. "Display robot"-Interaction between humans and anthropomorphized objects. In Proceedings of the RO-MAN 2007-The 16th IEEE International Symposium on Robot and Human Interactive Communication, Jeju Island, Korea, 26-29 August 2007; pp. 451-456.

18. Nomura, T.; Kanda, T.; Suzuki, T. Experimental investigation into influence of negative attitudes toward robots on human-robot interaction. Ai Soc. 2006, 20, 138-150. [CrossRef]

19. Mumm, J.; Mutlu, B. Human-robot proxemics: Physical and psychological distancing in human-robot interaction. In Proceedings of the 6th International Conference on Human-Robot Interaction, Lausanne, Switzerland, 6-9 March 2011; pp. 331-338.

20. Glas, D.F.; Minato, T.; Ishi, C.T.; Kawahara, T.; Ishiguro, H. Erica: The erato intelligent conversational android. In Proceedings of the 2016 25th IEEE International Symposium on Robot and Human Interactive Communication (RO-MAN), New York, NY, USA, 26-31 August 2016; pp. 22-29.

21. Ishi, C.T.; Liu, C.; Ishiguro, H.; Hagita, N. Evaluation of formant-based lip motion generation in tele-operated humanoid robots. In Proceedings of the 2012 IEEE/RSJ International Conference on Intelligent Robots and Systems (IROS), Algarve, Portugal, 7-12 October 2012; pp. 2377-2382.

22. Sakai, K.; Minato, T.; Ishi, C.T.; Ishiguro, H. Speech driven trunk motion generating system based on physical constraint. In Proceedings of the 2016 25th IEEE International Symposium on Robot and Human Interactive Communication (RO-MAN), New York, NY, USA, 26-31 August 2016; pp. 232-239.

23. Aron, A.; Aron, E.N.; Smollan, D. Inclusion of other in the self scale and the structure of interpersonal closeness. J. Personal. Soc. Psychol. 1992, 63, 596. [CrossRef]

24. Enomoto, H. Psychological Study of Self-Disclosure; Kitaohji Syobo: Kyoto, Japan, 1997. (In Japanese)

25. Beckman, M. Segment duration and the 'Mora' in Japanese. Phonetica 1982, 39, 113-135. [CrossRef]

26. Ward Jr, J.H. Hierarchical grouping to optimize an objective function. J. Am. Stat. Assoc. 1963, 58, $236-244$. [CrossRef]

27. Rigdon, M.; Ishii, K.; Watabe, M.; Kitayama, S. Minimal social cues in the dictator game. J. Econ. Psychol. 2009, 30, 358-367. [CrossRef]

28. Dindia, K.; Allen, M. Sex differences in self-disclosure: A meta-analysis. Psychol. Bull. 1992, $112,106$. [CrossRef]

29. Derlega, V.J.; Chaikin, A.L. Sharing Intimacy: What We Reveal to Others and Why; Prentice-Hall: Upper Saddle River, NJ, USA, 1975.

30. Eagly, A.H.; Wood, W.; Diekman, A.B. Social role theory of sex differences and similarities: A current appraisal. Dev. Soc. Psychol. Gend. 2000, 12, 174.

31. Yumi, T. Self-disclosure and loneliness in college student frendship. Psychol. Consult. Cent. Annu. Rep. 2011, 6, 15-22. (In Japanese)

32. Barnlund, D.C. Communicative Styles of Japanese and Americans: Images and Realities; Wadsworth/Thomson Learning: Belmont, CA, USA, 1989.

33. Nakanishi, M. Perceptions of self-disclosure in initial interaction: A Japanese sample. Hum. Commun. Res. 1986, 13, 167-190. [CrossRef]

34. Darling, K. 'Who's Johnny?' Anthropomorphic Framing in Human-Robot Interaction, Integration, and Policy. (March 23, 2015). ROBOT ETHICS 2.0; Oxford University Press: Oxford, UK, 2015; Volume 2.

35. Aroyo, A.M.; Rea, F.; Sandini, G.; Sciutti, A. Trust and Social Engineering in Human Robot Interaction: Will a Robot Make You Disclose Sensitive Information, Conform to Its Recommendations or Gamble? IEEE Robot. Autom. Lett. 2018, 3, 3701-3708. [CrossRef]

36. Ladegaard, H.J. Audience design revisited: Persons, roles and power relations in speech interactions. Lang. Commun. 1995, 15, 89-101. [CrossRef] 
37. Hutchby, I. Media Talk: Conversation Analysis and the Study of Broadcasting; McGraw-Hill Education (UK): London, UK, 2005.

38. Weber, S.J.; Cook, T.D. Subject effects in laboratory research: An examination of subject roles, demand characteristics, and valid inference. Psychol. Bull. 1972, 77, 273. [CrossRef]

39. Kintz, B.; Delprato, D.; Mettee, D.; Persons, C.; Schappe, R. The experimenter effect. Psychol. Bull. 1965, 63, 223. [CrossRef] [PubMed]

(C) 2020 by the authors. Licensee MDPI, Basel, Switzerland. This article is an open access article distributed under the terms and conditions of the Creative Commons Attribution (CC BY) license (http://creativecommons.org/licenses/by/4.0/). 